\title{
A Critical analysis of Non-ideal Quasi Z Source Inverter considering with parasitic resistances
}

\author{
Satyavani.N , C.Kamal Basha, N.Visali
}

\begin{abstract}
This paper describes the perfect small signal mathematical modeling of a non-ideal quasi-Z-source inverter (q-ZSI) by considering the parasitic resistances of capacitors and inductors. In this work, the detailed transfer function model of the system is derived mathematically by using state-space averaging method under continuous conduction mode (CCM). The deduced transfer function model exhibits the non-minimum phase of a system in the capacitor voltage-to-control transfer function due to the presence of Right-Half-Plane (RHP) zeros. The RHP zeros could impose a limitation on the controller design. Therefore, the effect of parasitic resistances of passive elements on system dynamics is analyzed with the frequency response plots such as Bode plot, Root locus and Pole-Zero maps. This analysis helps to frame the guidelines for selecting the pertinent values of passive components and their parasitic resistances. The system stability and dynamic response of the presented small signal model are compared with circuit model and validated in Mat lab/Simulink environment
\end{abstract}

Keywords: non-ideal quasi-ZSI, small-signal model, dynamic response, Right half plane (RHP) zero, non- minimum- phase.

\section{INTRODUCTION}

The economic expansion of a country depends on the production of electricity. Currently, the electricity is engendered with fossil fuels (like coal, gas, diesel etc) with a share of $66.30 \%$ and, renewable energy sources with a share of $31.7 \%$ respectively [1]. Now, it's time to increase electricity production with renewable sources to alleviate the negative aspects of traditional energy sources like pollution, depleting in nature and environmentally hazardous etc. [2].The non-conventional energy sources mainly depend on the meteorological conditions. The controlling of power systems is difficult since it has discrimination in characteristics, the unpredictability of the sources owing to the lack of load control. Thus, a power controlling unit like inverter plays a leading role in power conversion stages like ac-dc/dc-dc/dc-ac. Typically, voltage source inverter (VSI)/current source inverter (CSI) are placed to perform

Manuscript published on November 30, 2019.

* Correspondence Author

Satyavani.N *, Research Scholar, Department of EEE, Jawaharlal Nehru Technological University, Anantapur, India. Email: satyavani.eee@gmail.com

Dr.C.KamalBasha, Professor, Department of EEE, Madanapalle Institute of Technology and Science, Madanapalle, India. Email: kamalbashac@mits.ac.in

Dr.N.Visali, Principal, Department of EEE, JNTUA College of engineering,Kalikiri,India.Email:nvisali@gmail.com, principal.cek@jntua.ac.in.

(C) The Authors. Published by Blue Eyes Intelligence Engineering and Sciences Publication (BEIESP). This is an open access article under the CC-BY-NC-ND license http://creativecommons.org/licenses/by-nc-nd/4.0/ the inversion operation in two-stages i.e., in the initial stage boosting operation of photovoltaic output voltage is done with the dc-dc converter, then in next stage inversion operation(dc-ac) takes place which result in increase of system size, cost, and losses consequently poor efficiency. To overcome all these difficulties F.Z.peng [3], [4] developed Z-source inverter (ZSI). Various topological configurations are derived from the ZSI network and presented in [5] - [8] among them q-ZSI is a network which includes the additional advantages of continuous input current, reduced stress on a capacitor and high gain. These features mainly attract the applications related to photovoltaic (PV) energy. The high gain or boosting is achieved with a shoot-through state by conduction of switches of the same leg at the same time. Various pulse width modulation techniques (PWM) are implemented to control the shoot-through (ST) duty ratio, presented in [9][12]. In simple boost control (SBC), the switching signals are generated by comparing the triangular carrier wave with a $3 \varphi$ sine wave. However, higher gains are not achieved in this control due to the constraints on voltage ratings of the switches. Whereas high voltage gain is achieved with maximum constant boost control, with less voltage stress across the passive components at some value of modulation index (M) by maintaining the ST duty ratio as constant and [13] presents the relative analysis of PWM schemes for the ZSI. Recently various researchers investigate the topological improvements of quasi-Z-source network(q-ZSN)to accomplish dc-dc/ac-ac/ac-dc conversions [14].Therefore, it is required to study about the various characteristics of qZSN such as sizing of passive components, dynamic response to system control, limitations and solutions. In this paper, the state space equations are derived by considering the internal voltage drops in shoot-through and non-shootthrough mode are discussed in section 2.The transfer functions related to capacitor voltage-to-control, inductorcurrent-to-control, capacitor voltage-to-output current, and inductor current-to-output current are derived in section 3.Section 4 presents the sensitivity analysis of the transfer function with the help of root locus, bode diagram and polozero plots. The effects of internal resistances, passive elements and shoot-through duty ratio on system stability are also discussed and findings are summarized in this section. Section 5 presents the validation of the derived small signal model with circuit model in Matlab/Simulink. The transfer functions (henceforth, abbreviated as TF) are obtained from the state space equations and also the system response is analyzed. The passive component sizing of quasi-ZSN and its limitations are studied with parameter sweeping approach. Finally, the proposed model is validated with the simulation results.

Published By:

Blue Eyes Intelligence Engineering and Sciences Publication (BEIESP)

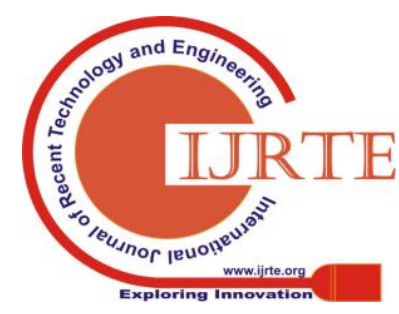




\section{A Critical analysis of Non-ideal Quasi Z Source Inverter considering with parasitic resistances}

\section{STEADY STATE OPERATION AND STATE SPACE AVERAGING OF NON IDEAL- QUASI-ZSI}

\section{A. Operating principle of quasi-Z-Source Inverter}

Fig.1 shows the basic non-ideal q-ZSI structure consisting of the diode (D), two inductors $\left(\mathrm{L}_{1}, \mathrm{~L}_{2}\right)$ and two capacitors $\left(\mathrm{C}_{1}, \mathrm{C}_{2}\right)$ with parasitic resistance of inductors $\left(\mathrm{r}_{1}, \mathrm{r}_{2}\right)$ and capacitance resistances $\left(\mathrm{R}_{1}, \mathrm{R}_{2}\right)$ respectively.

The input to the network $\left(\mathrm{V}_{\text {in }}\right)$ is of any D.C source like PV panel, fuel cell or batteries. The q-ZSI conducts in shoot-through (ST) and non-shoot- through (NST) modes as shown in Fig. 2. The following assumptions are made for the entire circuit analysis in this paper:

a) The resistors, inductors, and capacitors are linear, frequency independent and time-invariant. (However, the parasitic resistances of inductors and capacitors are taken once the transfer functions are obtained in the impedance form.)

b) The inverter switches MOSFET/IGBT and the diode is ideal.

c) For simplification of mathematical analysis of small signal model, consider that $\mathrm{L}_{1}=\mathrm{L}_{2}=\mathrm{L} ; \mathrm{C}_{1}=\mathrm{C}_{2}=\mathrm{C} ; \mathrm{r}_{1}=\mathrm{r}_{2}=\mathrm{r}$; and $\mathrm{R}_{1}=\mathrm{R}_{2}=\mathrm{R}$.

d) Define that ' $T$ ' is the time period over a one switching cycle ${ }_{T=T_{0}+T_{1}}$, where ' $T_{0}$ ' and ' $T_{1}$ ' are the time period of ST and NST states respectively. Therefore, the shoot-through duty ratio $\mathrm{D}_{0}=\mathrm{T}_{0} / \mathrm{T}$.

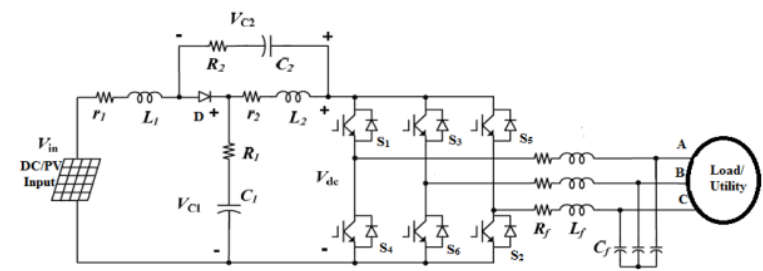

Fig. 1.Basic configuration of quasi ZSI connected to Load with an LC Filter.

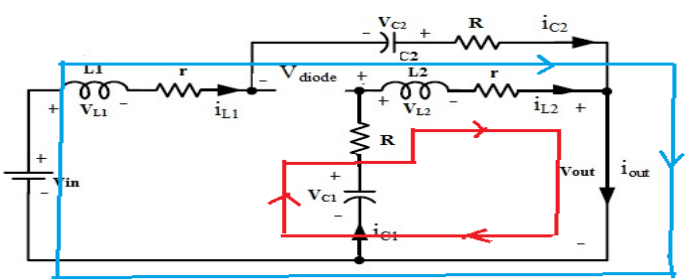

(a)

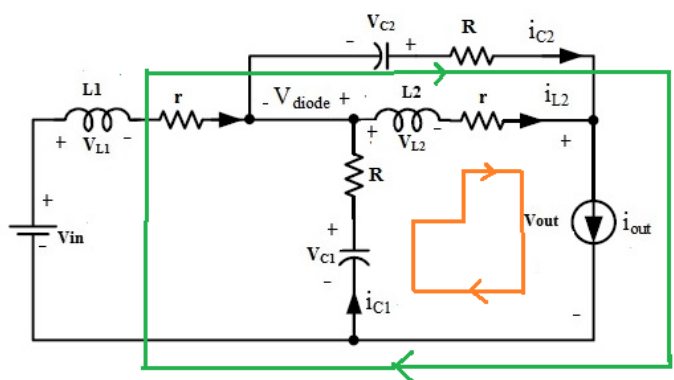

(b)

\section{(a). Shoot-through Mode}

From Fig.2 (a) the ST mode compels the diode to act in reverse biased condition. This leads to short-circuiting across the load and the energy stored in capacitors is transferred to the inductors. At the same time, the output voltage across the load is nearly zero. The voltage across the inductors, diode, and load during ST mode are given as:

$\left\{\begin{array}{l}V_{L_{1}}=-(R+r) i_{L_{1}}+V_{C_{2}}+V_{\text {in }} \\ V_{L_{2}}=-(R+r) i_{L_{2}}+V_{C_{1}} \\ V_{\text {out }}=0, V_{\text {diode }}=-\left(V_{C_{1}}+V_{C_{2}}\right)\end{array}\right.$

Since the diode is reverse biased, the capacitor and output currents are given as

$\left\{\begin{array}{c}i_{C_{1}}=-i_{L_{2}} \\ i_{C_{2}}=-i_{L_{1}} \\ i_{\text {out }}=i_{L_{1}}+i_{L_{2}}\end{array}\right.$

Where $\mathrm{R}, \mathrm{r}$ are the parasitic resistance of capacitor and inductor respectively. The $i_{c 1}, i_{c 2}, i_{L 1}, i_{L 2}$ are the current through the quasi-Z- source capacitors and inductors. The $i_{\text {out }}$ and $v_{\text {out }}$ are the output current and voltage respectively. The $V_{L 1}, V_{L 2}, V_{C 1}, V_{C 2}, V_{\text {diode }}$ and $v_{\text {out }}$ are the voltage across inductors, capacitors, diode and the load respectively. Re arranging (1)-(2) in matrix form, the state space equations of the q-Z- source network are given as in (3)

$$
\frac{d x}{d t}=\dot{X}=A_{1} X(t)+B_{1} U(t)
$$

Where $X=\left[\begin{array}{llll}i_{L 1} & i_{L 2} & V_{C 1} & V_{C 2}\end{array}\right]^{T}, U(t)=\left[\begin{array}{ll}i_{\text {out }} & V_{\text {in }}\end{array}\right]^{T}$

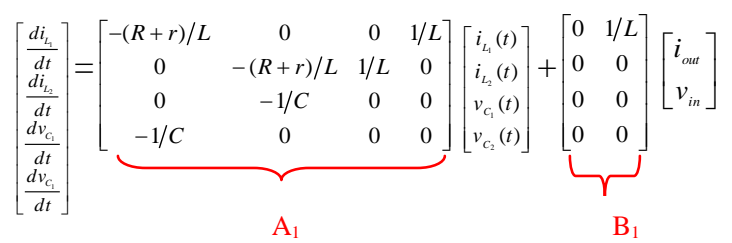

\section{(b). Non-Shoot-through Mode}

During NST mode the inverter bridge functioned as normal voltage source inverter and the diode is forced to act in forward bias direction. From Fig. 2(b) the voltage across the inductors, diode and load are given as

$$
\left\{\begin{array}{l}
V_{L_{1}}=-(R+r) i_{L_{1}}-V_{C_{1}}+V_{\text {in }}+i_{\text {out }} R \\
V_{L_{2}}=-(R+r) i_{L_{2}}-V_{C_{2}}+i_{\text {out }} R \\
V_{\text {out }}=V_{C_{1}}+V_{C_{2}} \\
V_{\text {diode }}=0
\end{array}\right.
$$

The diode current and capacitor currents are expressed in terms of the inductor and dc-link currents. i.e. $\left\{\begin{array}{l}i_{C_{1}}=i_{L_{1}}-i_{\text {out }} \\ i_{C_{2}}=i_{L_{2}}-i_{\text {out }}\end{array}\right.$

Fig. 2.Equivalent circuit of q-ZSI in (a) shoot-through mode (b) Non-shoot-through mode 
$i_{\text {diode }}=i_{L_{1}}+i_{L_{2}}-i_{\text {out }}$

Re arranging the expressions (5)-(6) in matrix form, the state space equations of the quasi-Z- source network are given as in (8)

$$
\frac{d x}{d t}=\dot{X}=A_{2} X+B_{2} U
$$

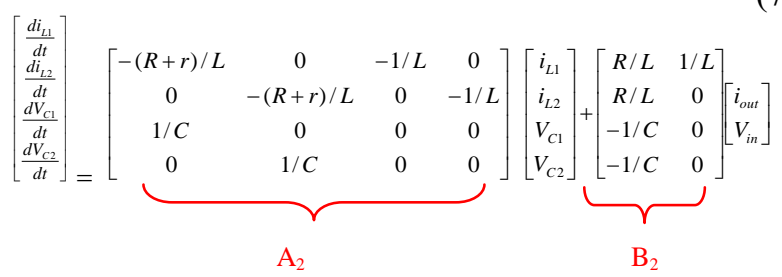

\section{B. State Space Averaging}

The average form of the quasi-Z- source network is obtained by multiplying the shoot-through state matrix $\left(\mathrm{A}_{1}\right)$ with shoot through duty ratio $\left(D_{0}\right)$ and non-shoot through state matrix $\left(A_{2}\right)$ with the compliment of $D_{0}$ (i.e. $\left.D_{0}^{1}=1-D_{0}\right)$.

$$
\frac{d X}{d t}=A X+B U, Y=C X+D U
$$

Where $\quad A=D_{0} A_{1}+\left(1-D_{0}\right) A_{2}$

$$
\begin{aligned}
& \therefore A=\left[\begin{array}{cccc}
\frac{-(R+r)}{L} & 0 & \frac{\left(D_{0}-1\right)}{L} & \frac{D_{0}}{L} \\
0 & \frac{-(R+r)}{L} & \frac{D_{0}}{L} & \frac{\left(D_{0}-1\right)}{L} \\
\frac{\left(1-D_{0}\right)}{C} & \frac{-D_{0}}{C} & 0 & 0 \\
\frac{-D_{0}}{C} & \frac{\left(1-D_{0}\right)}{C} & 0 & 0
\end{array}\right] \\
& B=D_{0} B_{1}+\left(1-D_{0}\right) B_{2} \\
& B=\left[\begin{array}{ll}
\left(1-D_{0}\right) R / L & 1 \\
\left(1-D_{0}\right) R / L & 0 \\
\left(D_{0}-1\right) / C & 0 \\
\left(D_{0}-1\right) / C & 0
\end{array}\right], C=\left[\begin{array}{llll}
0 & 0 & 1 & 0 \\
1 & 0 & 0 & 0
\end{array}\right], \quad D=\left[\begin{array}{l}
0 \\
0
\end{array}\right]
\end{aligned}
$$

\section{Steady- state Equations}

Ideal QZSI: The steady state solution of (9) by ignoring the resistances of inductor and capacitors are given as follows:

$$
\begin{gathered}
V_{C 1}=\frac{1-D_{0}}{1-2 D_{0}} V_{\text {in }} \\
V_{C 2}=\frac{D_{0}}{1-2 D_{0}} V_{\text {in }} \\
i_{L 1}=i_{L 2}=\frac{1-D_{0}}{1-2 D_{0}} i_{\text {out }} \\
V_{\text {out }}=\left[\frac{1}{1-2 D_{0}}\right] V_{\text {in }}
\end{gathered}
$$

Non-Ideal QZSI: The steady state solution of (9) by considering the resistance of inductor and capacitors are given as follows:

$$
\begin{aligned}
& V_{C 1}=\frac{1-D_{0}}{1-2 D_{0}} \mathrm{~V}_{\text {in }}-\frac{\left(1-D_{0}\right)\left(r+2 D_{0} R\right)}{\left(1-2 D_{0}\right)^{2}} i_{\text {out }} \\
& V_{C 2}=\frac{D_{0}}{1-2 D_{0}} V_{\text {in }}-\frac{\left(1-D_{0}\right)\left(r+2 D_{0} R\right)}{\left(1-2 D_{0}\right)^{2}} i_{\text {out }} \\
& i_{L 1}=i_{L 2}=\frac{1-D_{0}}{1-2 D_{0}} i_{\text {out }}
\end{aligned}
$$

$$
V_{\text {out }}=\left[\frac{1}{1-2 D_{0}}\right] V_{\text {in }}-\frac{2\left(1-D_{0}\right)\left(r+2 D_{0} R\right)}{\left(1-2 D_{0}\right)^{2}} i_{\text {out }}
$$

\section{SMALL SIGNAL MODELING OF THE NON-IDEAL Q-ZSI AND TRANSFER FUNCTIONS}

To analyze a small-signal model of non-ideal q-ZSI in detail a small perturbation is applied to $\hat{V}_{\text {in }}$ and duty ratio $\hat{D}_{0}$. After perturbation the input voltage and ST duty ratio becomes $V_{\text {in }}(t)=V_{\text {in }}+\hat{V}_{\text {in }}(t)$ and $D_{0}(t)=D_{0}+\hat{D}_{0}(t)$ respectively. The changes in the perturbation lead to small signal variations in state variables $\hat{\hat{x}}=\left[\hat{i}_{L 1}, \hat{i}_{L 2}, \hat{V}_{C 1}, \hat{V}_{C 2}\right]^{T}$, input variables $\hat{u}=\left[\hat{i}_{\text {out }}, \hat{V}_{\text {in }}\right]^{T}$ and duty ratio $\hat{D}_{0}$.

$F \dot{X}+F \hat{\dot{x}}=\left(D_{0} A_{1}+D_{0}^{1} A_{2}\right) X+\left(D_{0} B_{1}+D_{0}^{1} B_{2}\right) U+\left(D_{0} A_{1}+D_{0}^{1} A_{2}\right) \hat{x}+\left(D_{0} B_{1}+D_{0}^{1} B_{2}\right) \hat{u}+\left(A X+B_{1} U-A_{2} X-B_{2} U\right) \hat{D}_{0}$

Now, the resultant equations with small signal modelling becomes

$F \dot{x}=A \hat{x}+B \hat{u}+\left[\left(A_{1}-A_{2}\right) X+\left(B_{1}-B_{2}\right) U\right] \hat{D}_{0}$

Where, $A_{1}-A_{2}=\left[\begin{array}{cccc}0 & 0 & 1 / L & 1 / L \\ 0 & 0 & 1 / L & 1 / L \\ -1 / C & -1 / C & 0 & 0 \\ -1 / C & -1 / C & 0 & 0\end{array}\right], B_{1}-B_{2}=\left[\begin{array}{cc}-R / L & 0 \\ -R / L & 0 \\ 1 / C & 0 \\ 1 / C & 0\end{array}\right]$

By substituting the values of matrices A,B from(9) and (14) in (13) the resultant state space equations are as follows:

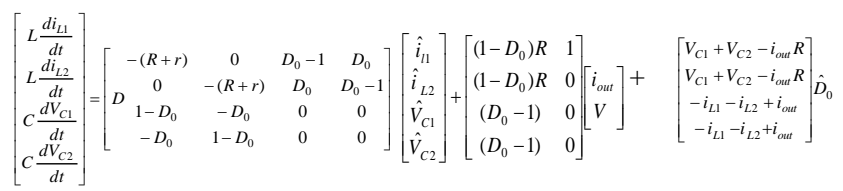

Equation (15) has been solved by using Laplace transformation to obtain current, voltages for inductor and capacitor respectively.

$\hat{i}_{L 1}(s)-\hat{i}_{L 2}(s)=\frac{S C}{S^{2}+(R+r) C S+1} \hat{V}_{i n}(s)$

$\hat{V}_{C 1}(s)-\ddot{V}_{C 2}(s)=\frac{1}{S^{2}+(R+r) C S+1} \hat{V}_{\text {in }}(s)$

From (16) and (17) the transfer function (T.F) for capacitor voltage and inductor current can be solved as

$$
\begin{aligned}
& \hat{V}_{C 1}(s)=\frac{K_{1}\left(D_{0}-1\right)+\left(1-2 D_{0}\right)\left(1-D_{0}\right)}{\left(K_{1}+1\right)\left[K_{1}+\left(1-2 D_{0}\right)^{2}\right]} V_{\text {in }}(s)+\frac{\left(1-2 D_{0}\right)\left(1-D_{0}\right) R+K_{2}\left(1-D_{0}\right)}{K_{1}+\left(1-2 D_{0}\right)^{2}} \hat{i}_{\text {out }}(s) \\
& +\frac{\left(1-2 D_{0}\right)\left(V_{C 1}+V_{C 2}-i_{\text {out }} R\right)+K\left(i_{\text {out }}-i_{L 1}-i_{l 2}\right)}{K_{1}+(1-2 D)^{2}} \hat{D}_{0}(s)
\end{aligned}
$$

$\hat{i}_{L 2}(s)=\frac{2 K_{1} D_{0}\left(1-D_{0}\right)}{K_{2}\left(K_{1}+1\right)\left[K_{1}+\left(1-2 D_{0}\right)^{2}\right]} \hat{V}_{\text {in }}(s)+\frac{K_{2}\left(1-D_{0}\right)\left(1-2 D_{0}\right)+K_{1} R\left(1-D_{0}\right)}{K_{2}\left[K_{1}+\left(1-2 D_{0}\right)^{2}\right]} \hat{i}_{\text {out }}(s)$

$+\frac{K_{2}\left(1-2 D_{0}\right)\left(i_{\text {out }}-i_{L 1}-i_{L 2}\right)+K_{1}\left(V_{C 1}+V_{C 2}-i_{\text {out }} R\right)}{K_{2}\left[K_{1}+\left(1-2 D_{0}\right)^{2}\right]} \hat{D}_{0}(s)$
Published By:

Blue Eyes Intelligence Engineering and Sciences Publication (BEIESP) 


\section{A Critical analysis of Non-ideal Quasi Z Source Inverter considering with parasitic resistances}

Where $K_{1}=L C S^{2}+(R+r) C S, K_{2}=L S+R+r$

Due to the asymmetrical structure of the quasi-ZSN the

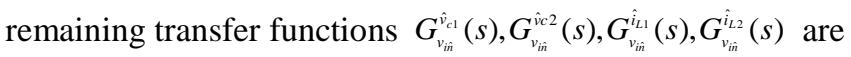
of fourth order. However the second order transfer function can be derived from $G_{\hat{v}_{\text {c }}}^{\hat{v}_{\text {csum }}}(s)$

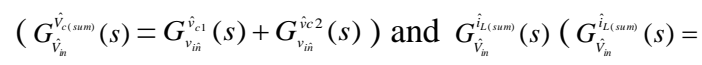$$
\left.G_{v_{\text {in }}}^{\hat{L}_{1}}(s)+G_{v_{v_{i j}}}^{\hat{L}_{2}}(s)\right) \text {. }
$$

Where

$$
\begin{aligned}
& G_{V_{\text {in }}}^{\hat{c}_{\text {csum }}}(s)=\frac{\hat{V}_{C(s \text { sum })}(s)}{\hat{V}_{\text {in }}(s)} \mid \hat{D}_{0}(s)=0, \hat{i}_{\text {out }}(s)=0 \\
& \therefore G_{\hat{V}_{\mathrm{in}}}^{\hat{\mathrm{c}}_{\text {(sum) }}}(s)=\frac{1-2 D_{0}}{L C s^{2}+C(R+r) S+\left(1-2 D_{0}\right)^{2}} \\
& G_{V_{\text {Vin }}}^{\hat{L}_{\text {Lsmm }}}(s)=\frac{\hat{i}_{L(\mathrm{sum})}(s)}{\hat{V}_{\text {in }}(s)} \mid \hat{D}_{0}(s)=0, \hat{i}_{\text {out }}(s)=0 \\
& \therefore G_{\hat{v}_{\text {Vin }}}^{\hat{v}_{\text {c(sur) }}}(s)=\frac{s C}{L C s^{2}+C(R+r) S+\left(1-2 D_{0}\right)^{2}}
\end{aligned}
$$

The transfer functions from ST duty ratio-tocapacitor voltage is same for both capacitors in the q-ZN and denoted as $G_{D \hat{0}}^{V \hat{c}}(s)$.Similarly the transfer functions from ST duty ratio-to-inductor currents $i_{L 1}$ and $i_{L 2}$ are identical and denoted as $G_{D \hat{0}}^{\hat{i}_{L}}(s)$.This will happen due to the symmetric energy exchanging process between the two capacitors and two inductors in the q-ZSN during the ST and NST states are alternating. Therefore, the transfer function from ST duty ratio-to-capacitor voltage $\left(G_{D \hat{0}}^{V \hat{c}}(s)\right)$, ST duty ratio to inductor current $\left(G_{D \hat{0}}^{\hat{i}_{L}}(s)\right)$, output current to capacitor voltage $\left(G_{\hat{i}_{\text {out }}}^{\hat{V}_{C}}(s)\right)$ and output current to inductor current $\left(G_{i_{\text {out }}^{\hat{i}_{L}}}(s)\right)$ are written as follows:

$$
\begin{aligned}
& \therefore G_{D \hat{0}}^{V c}(s)=\frac{\hat{V}_{C}(s)}{\hat{D}_{0}(s)} \mid \hat{i}_{\text {out }}(s)=0, \hat{V}_{\text {in }}(s)=0 \\
& =\frac{\left(V_{C 1}+V_{C 2}-R i_{\text {out }}\right)\left(1-2 D_{0}\right)+\left(i_{\text {out }}-i_{L 1}-i_{L 2}\right)(L s+R+r)}{L C s^{2}+s C(R+r)+\left(1-2 D_{0}\right)^{2}} \\
& G_{D \hat{0}}^{\hat{i}_{L}}(s)=\frac{\hat{i}_{L}(s)}{\hat{D}_{0}(s)} \mid \hat{i}_{\text {out }}(s)=0, \hat{V}_{\text {in }}(s)=0 \\
& =\frac{\left(V_{C 1}+V_{C 2}-R i_{\text {out }}\right) C s-\left(i_{\text {out }}-i_{L 1}-i_{L 2}\right)\left(1-2 D_{0}\right)}{L C s^{2}+C(R+r) s+\left(1-2 D_{0}\right)^{2}} \\
& G_{i_{\text {out }}}^{\hat{V}_{C}}(s)=\frac{\hat{V}_{C}(s)}{\hat{i}_{\text {out }}(s)} \mid \hat{D}_{0}(s)=0, \hat{V}_{\text {in }}(s)=0 \\
& =\frac{R\left(1-D_{0}\right)\left(1-2 D_{0}\right)-\left(1-D_{0}\right)[s L+r+R]}{L C s^{2}+C(R+r) s+\left(1-2 D_{0}\right)^{2}} \\
& G_{\hat{i}_{\text {out }}}^{\hat{i}_{L}}(s)=\frac{\hat{i}_{L}(s)}{\hat{i}_{\text {out }}(s)} \mid \hat{D}_{0}(s)=0, \hat{V}_{\text {in }}(s)=0 \\
& =\frac{C R\left(1-D_{0}\right)+\left(1-D_{0}\right)\left(1-2 D_{0}\right)}{L C s+C(R+r) s+\left(1-2 D_{0}\right)^{2}}
\end{aligned}
$$

From the TF $G_{D \hat{0}}^{v \hat{c}}(s)$ the term $\left(i_{\text {out }}-i_{L 1}-i_{L 2}\right)$ is negative since $^{\left(i_{\text {out }}<\left(-i_{L 1}-i_{L 2}\right)\right)}$. Hence the zeros lie on the right half of the plane(RHP) and poles are lies on left half of the plane (LHP).If any system is having zeros on RHP then it is called non-minimum phase system. So for RHP zeros system controller designing is crucial. Moreover, stability of RHP zeros will be analyzed with Root locus and Bode plot in further sections.

\section{A. Dynamic characteristics}

From the small signal modelling of the non-ideal q-ZSI the characteristic equation is

$$
s^{2}+\frac{R+r}{L} s+\frac{\left(1-2 D_{0}\right)^{2}}{L C}=0
$$

Compare (26) with standard characteristic equation of second order system (27)

$$
\begin{aligned}
& s^{2}+2 \xi \omega_{n} s+\omega_{n}^{2}=0 \\
& \therefore \omega_{n}=\frac{1-2 D_{0}}{\sqrt{L C}}, \xi=\frac{R+r}{2\left(1-2 D_{0}\right)} \sqrt{\frac{C}{L}}
\end{aligned}
$$

From the expressions of natural frequency $\left(\omega_{n}\right)$ and damping ratio $(\xi)$, it clearly shows that the shoot through duty ratio, inductance and capacitance affects the system dynamic behaviour.

\section{SENSITIVITY ANALYSIS OF THE TRANSFER FUNCTIONS OF NON IDEAL Q-ZSN}

This section describes the effects of parameters on non-ideal q-ZSI system and is analyzed with the help of frequency response plots such as Root locus, pole-zero map and Bode plot. The sensitivity of the proposed small signal transfer functions are dependent on the parameters like L, C, r, R and $\mathrm{D}_{0}$. The stability of the proposed system gets affected by the perturbations in the state variables and $\mathrm{D}_{0}$. Apart from this the parasitic resistances of inductors and capacitors also affects the dynamics and system stability and the findings are summarized in the Table I.

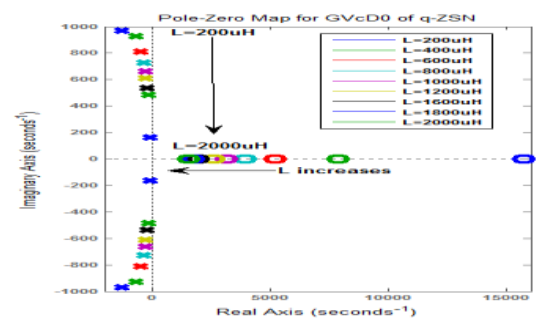

(a)

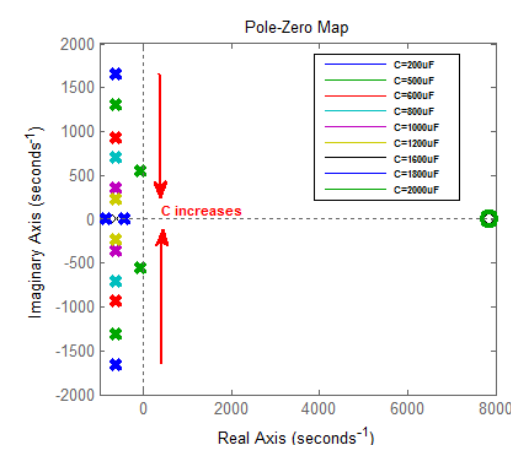

(b) 


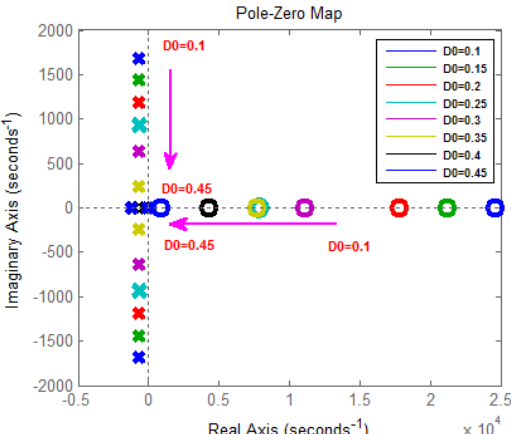

(c)
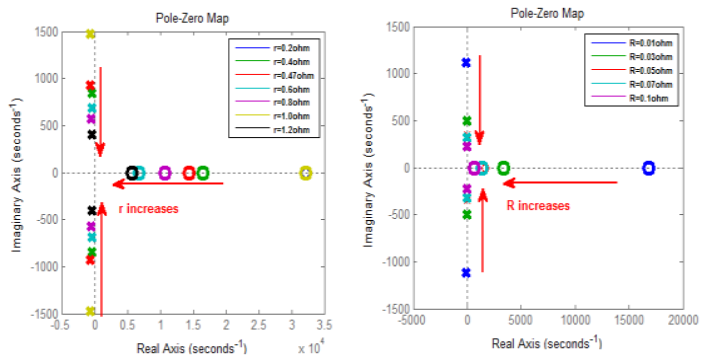

(d)

Fig. 3.Ploe-Zero map for the transfer function $G_{D \hat{0}}^{v \hat{c}}(s)$ for different values of (a) Inductance (b) Capacitance (c) Shoot-through-duty ratio(d) Parasitic resistance of inductor and capacitor
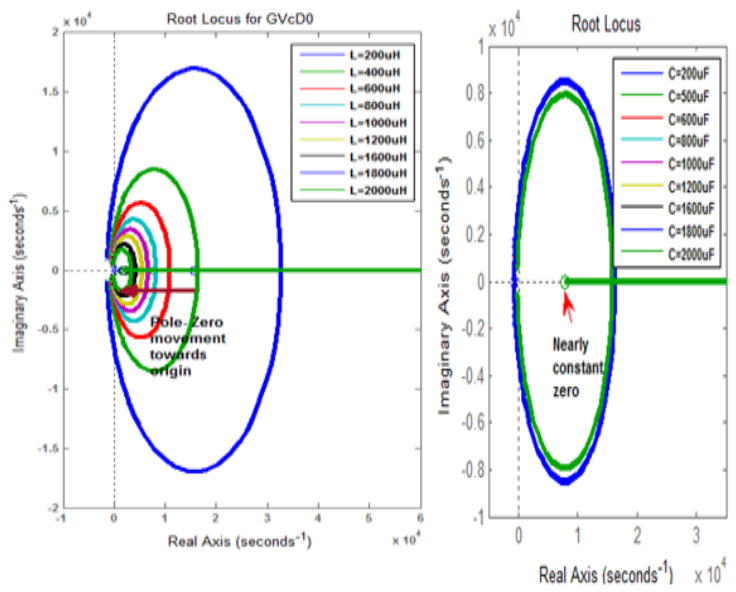

(a)

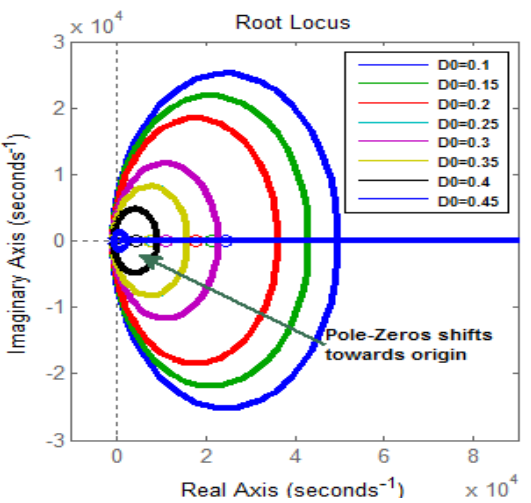

(b)
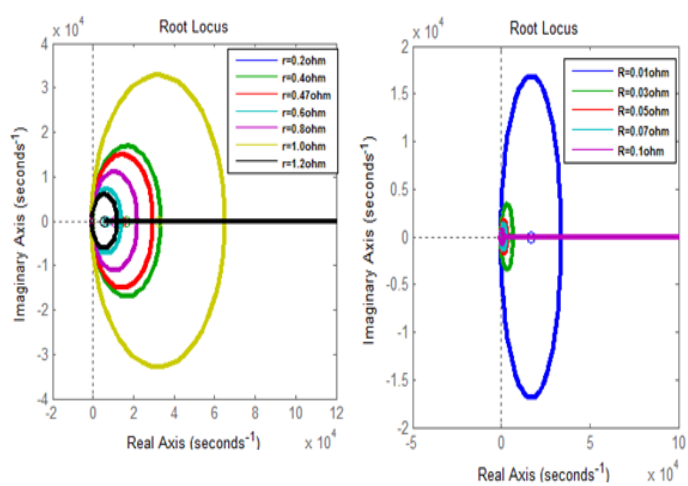

(c)

Fig. 4.Rootlocus for the transfer function $G_{D \hat{0}}^{v \hat{c}}(s)$ for different values of (a) Inductance and Capacitance (b) Shoot-through-duty ratio(c) Parasitic resistance of inductor and capacitor
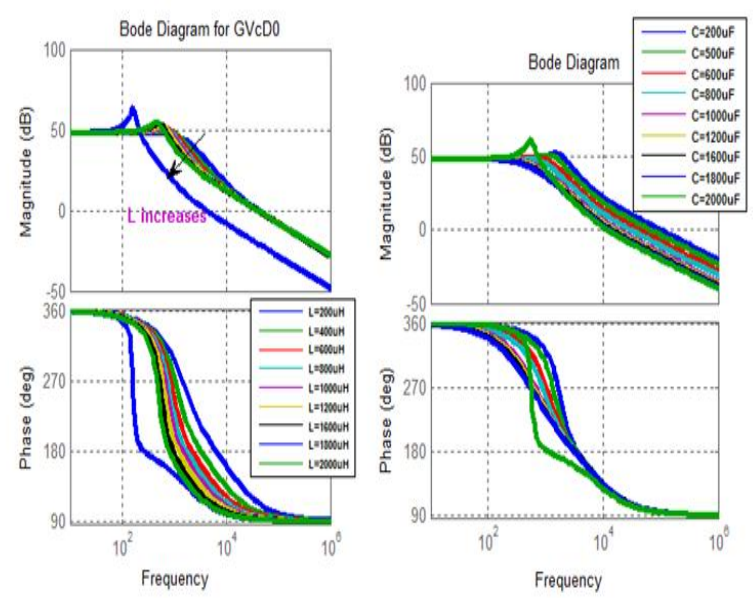

(a)

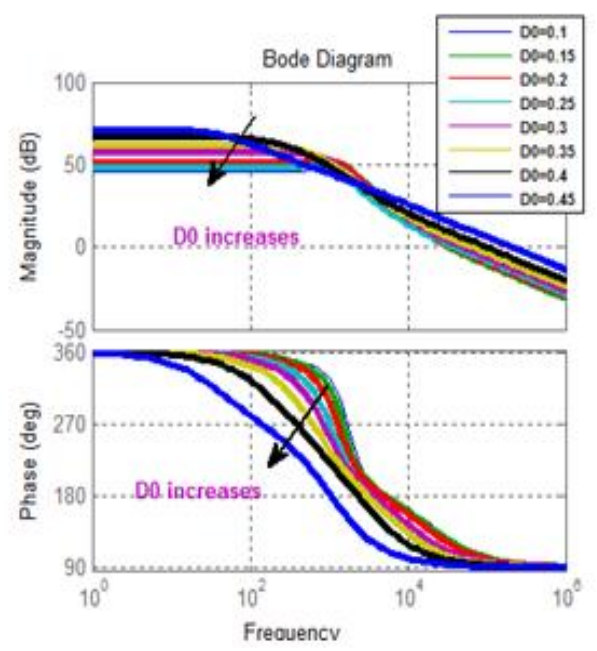

(b)

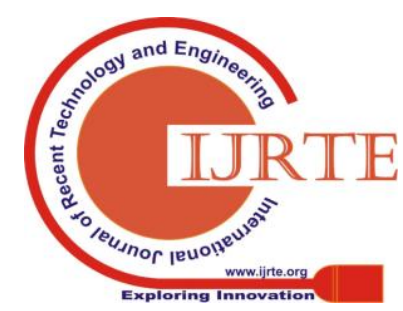



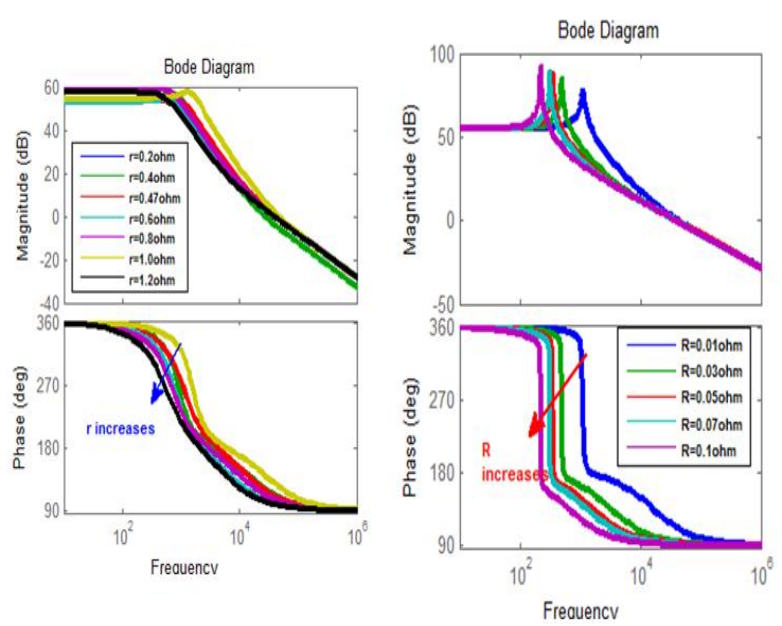

(c)

Fig. 5.Bode plor for the transfer function $G_{D \hat{0}}^{v \hat{c}}(s)$ for different values of (a) Inductance and Capacitance (b) Shoot-through-duty ratio(c) Parasitic resistance of inductor and capacitor
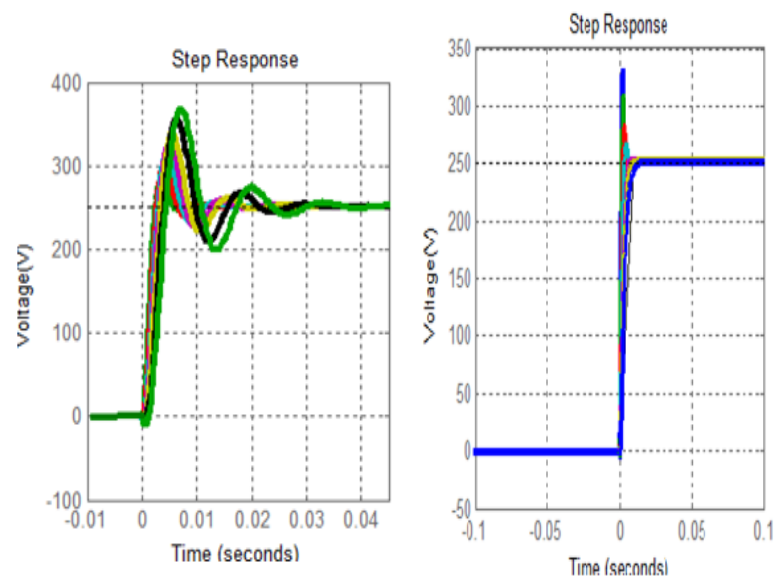

Fig. 6.Step Response for the transfer function $G_{D \hat{0}}^{v \hat{c}}(s)$ for different values of Inductance and Capacitance

A. Effect of variations in passive elements ( $L$ and $C$ ) on system dynamics of q-ZSN

From Fig.3. When 'L (inductance)' is increasing, the movement of complex poles and zeros shifts from the RHP towards the origin indicating an increase in the degree of a non-minimum phase of the system. Whereas an increase in the value of ' $\mathrm{C}$ (Capacitance)' results that there is a minute variation in RHP zeros and the complex conjugate poles shifts nearer to the origin. The corresponding Bode plots are shown in the Fig.5. It is clear that the increase in inductance leads to faster response with a reduction in corner frequency and peak -overshoot. Whereas the increase in C, leads to an increase in the value of $\xi$ (damping ratio) increases but a reduction in the frequency and peak overshoot. Hence, the amplitude characteristics change is steeply.

\section{B. Effect of variations in shoot-through duty ratio $\left(D_{0}\right)$ on system dynamics of q-ZSN}

From pole-zero map Fig.3. (c), When shoot-through duty ratio $\left(D_{0}\right)$ increases, the movement of RHP zeros and complex conjugate poles shifted to the origin indicating the non -minimum phase behavior of the system. From the Bode-plots Fig.5 (b) it is evident that an increase of shootthrough duty ratio reduces the corner frequency.

\section{Effect of variations in parasitic resistance(r and $R$ ) on system dynamics}

From Fig.3 it shows that the system damping varies with the parasitic resistances of passive elements. As ' $r$ ' increases the complex poles and zeros in right half-plane shifts nearer to the origin and the system damping decreases. Whereas an increase of $\mathrm{R}$ drags the complex poles from RHP towards the origin along with the real axis and very less variation in RHP zeros. The system damping increases with the increase of $\mathrm{R}$ value. From the analysis, the impact of parameter changes such as $\mathrm{L}, \mathrm{C}, \mathrm{D}_{0}, \mathrm{r}, \mathrm{R}$ in the non-ideal quasi-ZSI dynamics is summarized in Table I. This analysis can be able to provide a direction for designers to implement the suitable components sizing of inverter and controller for PV applications.

\section{Passive component selection}

For the proposed system, during a shoot-through time the capacitors charge the inductors hence the same current flows through both of them. Therefore, the capacitance can be calculated by the following:

$$
C=\frac{P_{0} D_{0}}{\Delta V_{c} V_{i n}}
$$

Where $\Delta V_{c}$ is the desired capacitance voltage ripple, $V_{\text {in }}$ is input voltage, $P_{0}$ is the output power and $D_{0}$ is the shootthrough duty cycle. Again, during a shoot-through period both voltages across inductors and capacitors are same. Then

$$
L=\frac{\hat{V}_{c} D_{0}}{\Delta i_{L}}
$$

Where ' $\Delta i_{L}$ ' is the inductor current ripple and $\hat{V}_{c}$ is the average capacitor voltage.

\begin{tabular}{|c|c|c|c|c|}
\hline \multirow[t]{2}{*}{ Parameter } & \multirow[t]{2}{*}{ Change } & \multicolumn{2}{|c|}{ Effect on position of } & \multirow[t]{2}{*}{ Impact on system Dynamics } \\
\hline & & Conjugate poles & Zeros & \\
\hline Inductance(L) & Increasing & $\begin{array}{l}\text { Shifts near to the } \\
\text { imaginary axis }\end{array}$ & $\begin{array}{l}\text { Shifts near to the } \\
\text { imaginary axis }\end{array}$ & $\begin{array}{ll}- & \text { Non-minimum phase undershoot increases. } \\
\text { - } & \text { Settling time increases } \\
\text { - } & \text { Damping ratio decreases } \\
& \text { Natural frequency decreases. }\end{array}$ \\
\hline
\end{tabular}

TABLE I. A CONCISE SUMMARY OF PARAMETER VARIATIONS ON THE QUASI-Z-SOURCE INVERTER DYNAMICS 


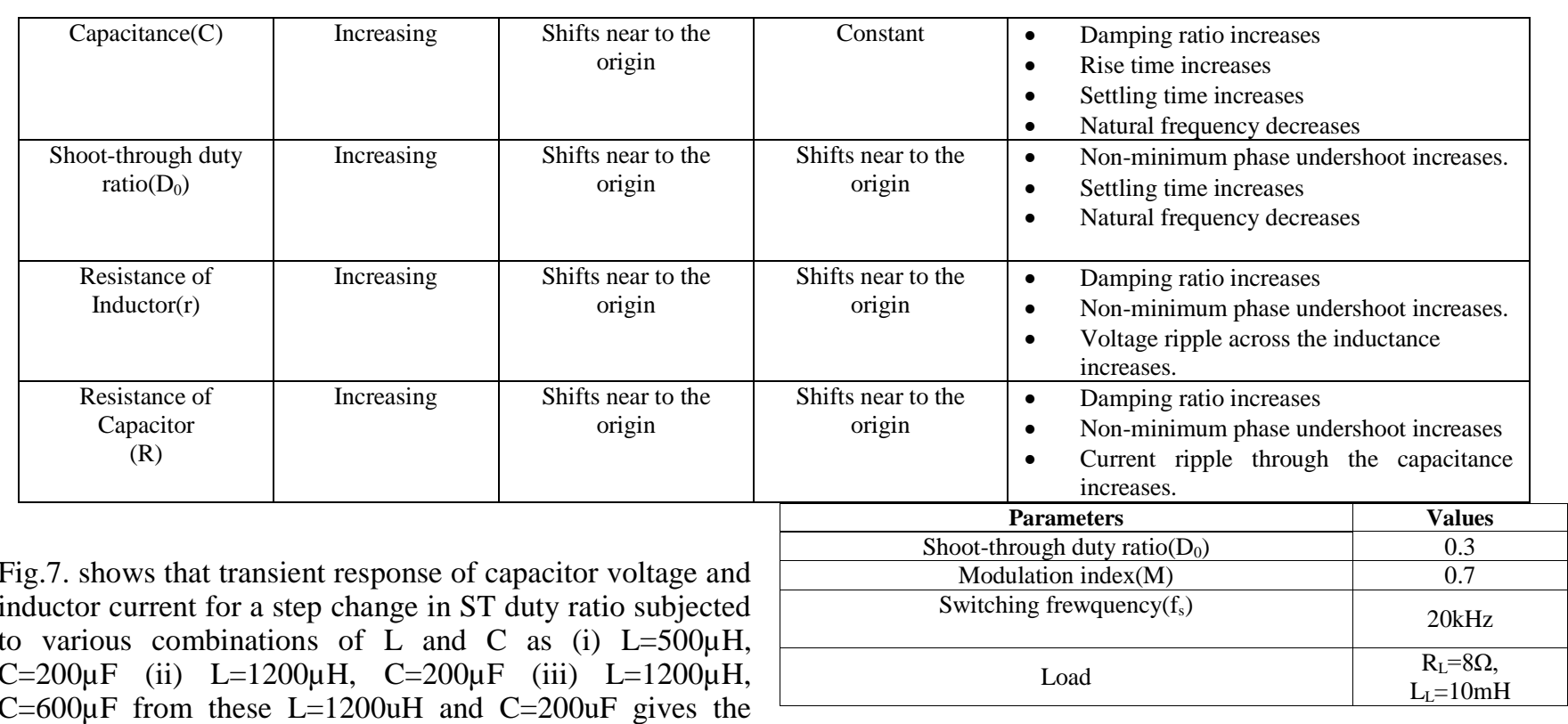
minimum peak overshoot and settling time. Hence, a conclusion can be drawn from the results of the Root locus, Bode plots and system response is, choose the passive components properly by considering the size of components, cost, damping factor, quality factor, ripple factor and phase margin in closed-loop control. The designers can also take the help from dynamic characteristics like peak overshoot, settling time, rise time for proper selection of $\mathrm{L}$ and $\mathrm{C}$. Hence, there must be the limit between $D_{0}$ for the required boost and the degree of a non-minimum phase of a system can sustain.

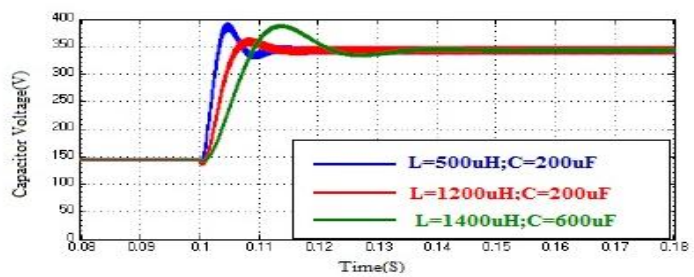

(a)

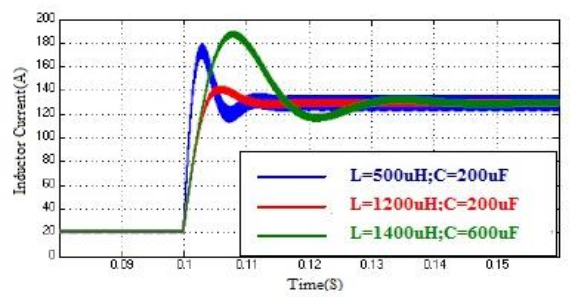

(b)

Fig. 7.Step response of a) Capacitor voltage and b) Inductor current for step change in $\hat{D}_{0}$ with varying $L$ and $C$.

\section{Simulation RESUlts}

TABLE II. SIMULATION PARAMETERS

\begin{tabular}{|c|c|}
\hline Parameters & Values \\
\hline Input Voltage $\left(\mathrm{V}_{\text {in }}\right)$ & $25 \mathrm{~V}$ \\
\hline Inductance $\left(\mathrm{L}_{1}, \mathrm{~L}_{2}\right)$ & $20 \mathrm{mH}$ \\
\hline Capaciance $\left(\mathrm{C}_{1}, \mathrm{C}_{2}\right)$ & $90 \mu \mathrm{F}$ \\
\hline Parasitic resistance of inductor(r) & $0.5 \Omega$ \\
\hline Parasitic resistance of capacitor $(\mathrm{R})$ & $0.3 \Omega$ \\
\hline
\end{tabular}

Published By:

Blue Eyes Intelligence Engineering and Sciences Publication (BEIESP) (C) Copyright: All rights reserved.
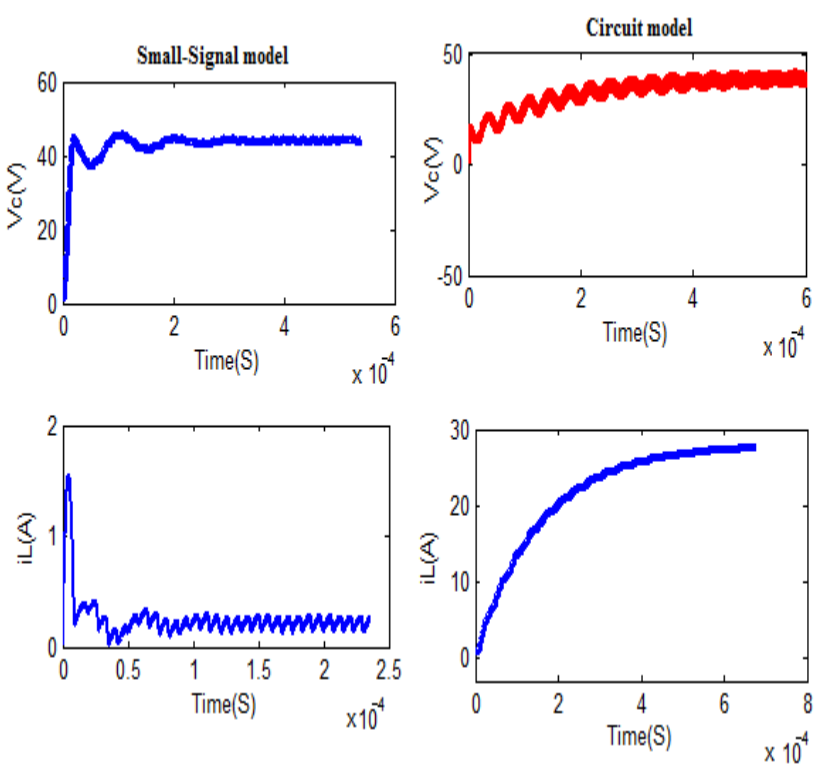

Fig. 8.Small signal and circuit model validation for voltage of capacitor and Inductor current

The simulation of the detailed circuit model is implemented in MATLAB/Simulink shown in Fig.9.The steady state wave forms like input voltage, capacitor voltage, inductor current, and output voltage are obtained as shown in Fig.10 from the circuit model for a shoot through duty ratio of 0.3 . 


\section{A Critical analysis of Non-ideal Quasi Z Source Inverter considering with parasitic resistances}

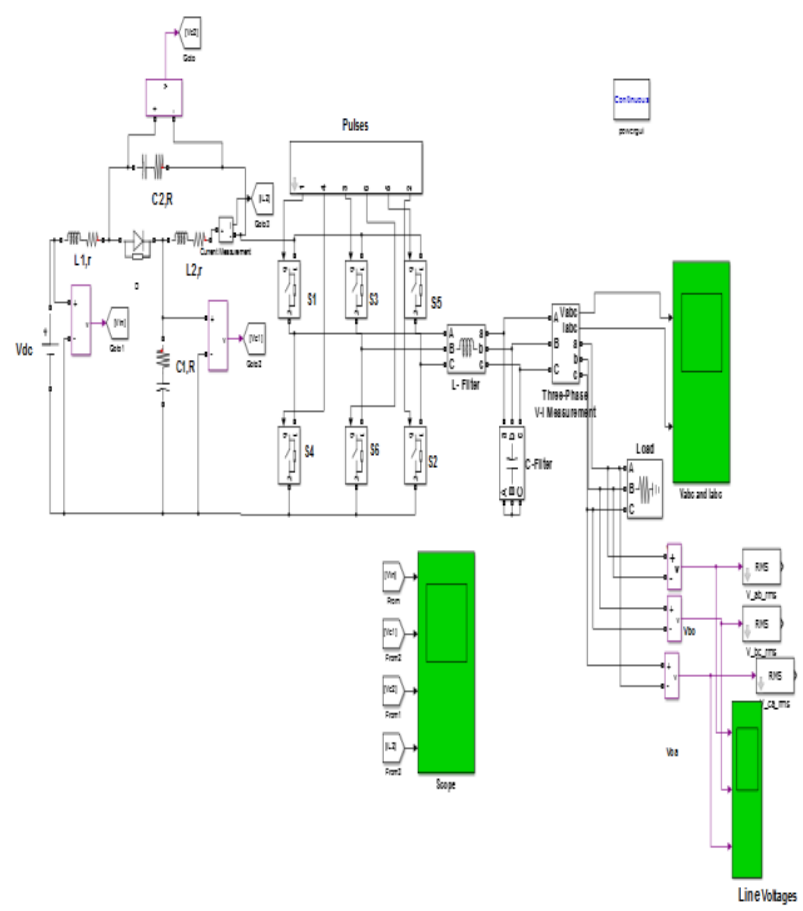

Fig. 9.Detailed circuit model of non-ideal quasi-ZSI implemented in MATLAB/Simulink
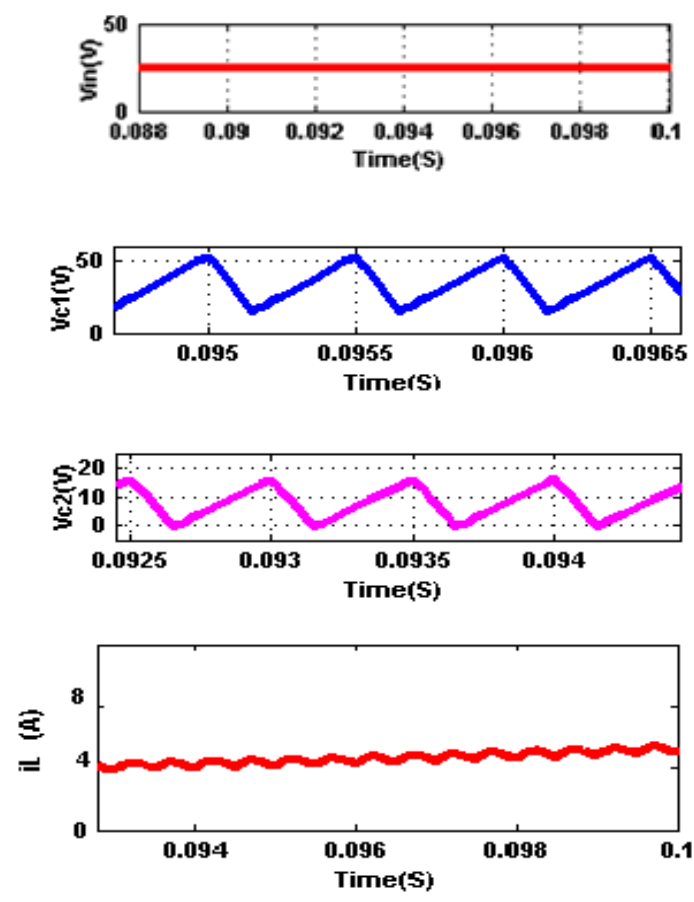

(a)

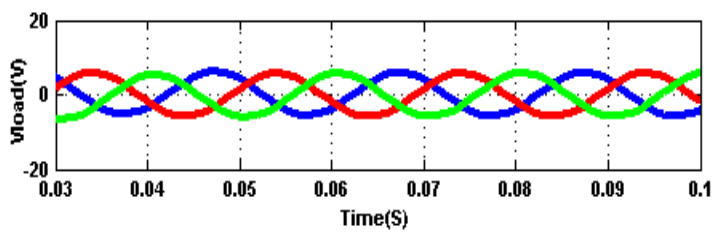

(b)

Fig. 10. Steady state waveforms of non-ideal quasi-ZSI with RL load simulation model (a) voltage of capacitor and Inductor current (b)Output voltage across the load

\section{CONCLUSION}

In this paper, the complete transient analysis of non-ideal q-ZSN with the parametric sweeping approach is presented. An accurate small signal model is developed for non-ideal quasi-ZSN to show the impact of passive elements ( $\mathrm{L}$ and $\mathrm{C})$, internal resistances( $\mathrm{R}$ and $\mathrm{r}$ ) and shoot through duty ratio on the performance of q-ZSN. From the proposed model, the transfer functions are derived by using the state-space averaging method and it shows that zeros lie on RHP of the system. The effectiveness of the derived transfer functions capacitor voltages, inductor currents-output, and location of RHP zeros and complex conjugate pole trajectories are investigated with time domain and frequency response plots. Thus, the presented design analysis indicates that by increasing inductance in the quasi $\mathrm{Z}$ - source network leads to increase the degree of a non-minimum phase of the system whereas an increase of capacitance leads to a very little effect on the degree of the non-minimum phase of the system and dynamic response becomes slow. Simulation results have been given to verify the small signal model of the non-ideal quasi ZSI with detailed circuit model of the system.

\section{REFERENCES}

1. S.Manju and NetramaniSagar, "Progressing towards the development of sustainable energy: Critical review on the current status,applications, developmental barriers and prospects of solar photovoltaic systems in India," Renewable and sustainable energy reviews, vol. 70, pp. 298-313, April 2017.

2. Moosavian SM, Rahim NA, Sevaraj J, and Solangi KH. "Energy policy to promote photovoltaic generation", Renew Sustain Energy Rev 2013,25(3),pp.44-58.

3. F.Z.Peng, "Z- source inverter", in Proc. Ind. Appl. Conf., Oct.1318,vol.2,pp.775-781,2002.

4. F.Z.Peng,"Z-sourceinverter,"IEEE Transactions on Industry Applications.,vol.39,no.2,pp.504-510,Mar/Apr.2003.

5. J.Rabkowski, "The bi directional Z-source inverter as an energy storage/grid interface", in Proc. Int. Conf." Computer as a tool, EUROCON,Sept.9-12,2007,pp.1629-1635.

6. K.Yu,F.L.Luo and M.Zhu, " Study of an improved Z-source inverter: Small signal analysis", in Proc.fifth IEEE Conf.Industrial Electronics and Applications,June15-17,2010,pp.2169-2174.

7. J.Anderson and F.Z.Peng, "A class of quasi Z-source inverters", in Proc.IEEE Industry Applications Society Annual Meeting,Oct.59,2008,pp.1-7.

8. J.Anderson and F.Z.Peng, " Four quasi Z-source inverters", in Proc.IEEE Power Electronics Specialists Conf.,PESC,June 1519,2008,pp.2743-2749.

9. F.Z.Peng,M.S.Shen and Z.M.Qian, “ Maximum boost control of the Zsource inverter",IEEE Transactions on Power Electronics,vol.20,pp.833-838,July 2005.

10. P.C.Loh,D.M..Vilathagamuwa,Y.Sen Lai,G.T.Chua and Wyle, “ PulseWidth modulation of Z-source inverters, "IEEE Transactions on Power Electronics,vol.20,pp.1346-1355,Nov 2005.

11. M.Shen,J.Wang,A.Joseph,F.Z.Peng,L.M.Tolbert and D.J.Adams, "Maximum constant boost control of the Z-source inverters", in Proc.IEEE IAS Annual meeting,Oct2004.

12. Y.Liu,B.Ge,H.A.Rub and F.Z.Peng, " Overview of space vector modulations for three phaseZ-source/Quasi-Z-source inverters",IEEE Trans.Power Electron.,vol.29,no.4,pp.2098-2108,Apr.2014.

13. Satyavani, N., and Visali, N,"A Review on MPPT Methods for ZSI based Photovoltaic Power Conversion System under Partial Shading Conditions", i-manager's Journal on Power Systems Engineering, 5(2), 43-52,2017.

14. Omar Ellabban and Haitham Abu-Rub,"Z-source inverter: Topology improvements review", IEEE Industrial Electronics Magazine,vol.10,no.1,pp.6-24,Mar.2016.

15. J.B.Liu,J.G.Hu and L.Y.Xu, " Dynamic modelling and analysis of Z source converter-derivation of ac small signal model and design oriented 
analysis",IEEETrans.on.Ind.Electron.,vol.54,no.4,pp.2352-

\section{9,Aug.2007}

16. Loh,Poh Chaiang,Vilathgamuwa,D.Mahinda,etal., “ Transient modelling and analysis of pulse width modulated Z-source inverter",IEEE Trans.on Power Electronics,vol.22,no.2,pp.498507,Mar.2007.

17. Li Yuan,F.Z.Peng,et al., “ Controller design for quasi Z-source inverter in photovoltaic systems", in IEEE Energy Conversion Congress and Exposition(ECCE),2010,pp.3187-3894.

\section{AUTHORS PROFILE}

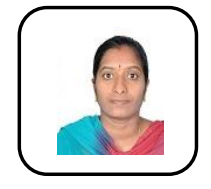

Satyavani.N received the B.Tech degree in Electrical and Electronics Engineering from JNT University, Hyderabad in 2006 and M.Tech degree in Power Electronics from JNT University Ananthapuramu in 2012. She is currently, pursuing the Ph.D. degree in Electrical Engineering under JNT University Ananthapuramu and working as an Assistant Professor at Madanapalle Institute of Technology and Science, Madanapalle. Her research interests include modeling and control of Z-source inverters, photovoltaic systems, power electronics and control of power electronics interfaces. She is a member of GIE.

Dr.C.KamalBasha received the B.Tech degree in Electrical and Electronics Engineering from JNT University, Hyderabad in 2002 and M.Tech degree in Control Systems from Pune University in 2004 and the Ph.D degree in Electrical Engineering from JNT University, Ananthapuramu in 2015. Currently, he is Professor at Madanapalle Institute of Technology and Science, Madanapalle. His research interests include control of power electronics and drives, Electrical power systems, power electronics.

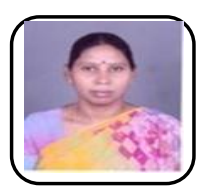

Dr.N.Visali received the B.Tech degree in Electrical and Electronics Engineering from JNT University, Hyderabad in 1994, M.Tech degree in Electrical Power Systems from KREC, Mangalore in 1998 and Ph.D degree in Electrical Engineering from JNT University, Ananthapuramu in 2013.Currently, she is principal of JNTUA College of Engineering, Kalikiri. Her research interests include Electrical power systems, Distribution systems, soft computing techniques, and power electronics. She is a member of ISTE (LM 48704), FIE, IAENG and IEEE

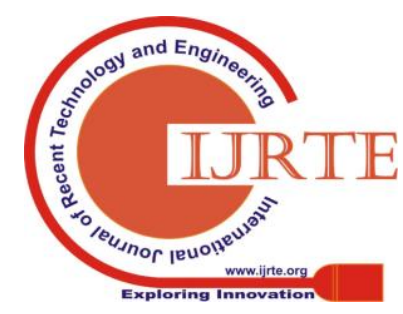

